\title{
REVIEW ARTICLE \\ Imaging endpoints for clinical trials in MacTel type 2
}

\author{
Daniel Pauleikhoff $\mathbb{D}^{1 凶}$, Laurenz Pauleikhoff ${ }^{2}$ and Emily Y. Chew $\mathbb{D}^{3}$ \\ (c) The Author(s), under exclusive licence to The Royal College of Ophthalmologists 2021
}

\begin{abstract}
INTRODUCTION: Macular Telangiectasia type 2 (MacTel) is a bilateral neurodegenerative disease associated with dysfunction in the serine and lipid metabolism resulting in loss of Muller cells and photoreceptors. Typical structural changes include vascular abnormalities, loss of retinal transparency, redistribution of macular pigment and thinning of the central retina with photoreceptor loss. The presence and extent of photoreceptor loss, as visible on Optical Coherence Tomography (OCT) ("disease severity scale"), correlate with functional loss and the limitation of photoreceptor loss appears to be the most promising therapeutic approach. Ongoing clinical trials of ciliary neurotrophic factor (CNTF) implants for the treatment of MacTel are using this outcome to evaluate efficacy. An ideal outcome measure provides the ability to quantify the extent of the disease progression with precision and reproducibility.
\end{abstract}

METHODS: This review describes the changes and findings on different imaging techniques including fluorescein- and OCT angiography, blue light reflectance, 1- and 2-wavelength autofluorescence and OCT.

RESULTS: The possibilities of objective quantification of the severity of MacTel and correlation with functional characteristics such as best-corrected visual acuity (BCVA) and microperimetry and their applications as quantitative imaging endpoints for clinical treatment trials are discussed. OCT and especially en face OCT could be demonstrated as precise and reproducible methods to quantify the area of photoreceptor loss, which correlated highly significantly with functional loss in microperimetry.

CONCLUSION: The analysis of the area of photoreceptor loss on en face OCT is the most reliable imaging endpoint for treatment trials in MacTel. This method is already being used in ongoing randomized trials.

Eye (2022) 36:284-293; https://doi.org/10.1038/s41433-021-01723-7

\section{INTRODUCTION}

Idiopathic Macular Telangiectasia Type 2 (MacTel) is a bilateral neurodegenerative disease of the retina that affects the visual function with initial paracentral scotomas and later loss of bestcorrected visual acuity (BCVA) [1]. The current pathogenetic concept suggests a dysfunction in the serine and lipid metabolism, resulting in a loss of Muller cells and photoreceptors, which leads to the characteristic clinical phenotype of MacTel [1-4]. Typical structural changes include vascular abnormalities, such as telangiectatic capillaries, dilated and right-angled veins on fluorescein angiography (FA), as well as loss of retinal transparency and redistribution of macular pigment [1, 5-11]. In addition, morphological changes visible in spectral domain-optical coherence tomography (SD-OCT) images are highly characteristic of this disease $[1,12]$. SD-OCT features include thinning of the central retina and low-reflective spaces ("cavities") in the inner and outer retina (OR). Another common finding is a focal loss of the ellipsoid zone (EZ), also known as inner segment (IS)/outer segment (OS) break, that typically starts temporal to the foveal centre, then progressively involves the fovea and later extends to nasal to the foveal centre [13-20]. More recently, further investigations into the vascular changes in the disease and its progression have been made possible using the non-invasive OCT-angiography [21-25]. Retinal alterations and dysfunction usually remain limited to an oval area centred on the fovea, with a horizontal diameter not exceeding the distance between the temporal optic disc margin and foveal centre, and the vertical diameter not exceeding approximately 0.8 times this distance ('MacTel area') [26]. The earliest changes develop in the temporal sector [27]. Even in late disease stages involving the entire MacTel area, the temporal sector usually remains the epicentre of the disease with the most pronounced alterations [28].

The different imaging methods reveal distinct aspects of the morphological and cellular changes in different stages of MacTel. They are additive in confirming the diagnosis, but are different in terms of quantification of disease severity. The aim of this review is to describe the specific aspects of different imaging methods to characterize MacTel changes and to compare their potential as imaging endpoints for clinical trials.

\section{Imaging techniques in MacTel}

Blue light reflectance. One of the earliest signs of MacTel is a loss of retinal transparency and a pattern of abnormal parafoveal reflectance caused by increased scattering in the inner retina $[6,10]$. Imaging with short wavelength light (blue light reflectance, BLR imaging) provides a tool for detecting and recording this phenomenon $[9,10,29,30]$. In early stages of the disease, an increase of reflectance may be visible temporal to the fovea, correlating with reduced macular pigment optical density (MPOD) in dual-wavelength autofluorescence (DWAF). With disease progression, the whole 'MacTel area' is demarcated by an oval area of increased reflectance (Fig. 1). The detectability of this

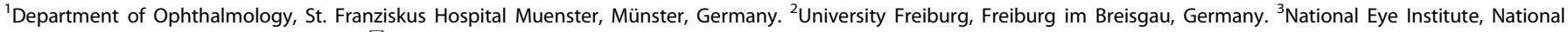
Institutes of Health, Bethesda, MD, USA. ${ }^{\bowtie}$ email: dapauleikhoff@muenster.de

Received: 15 June 2021 Revised: 15 July 2021 Accepted: 26 July 2021

Published online: 13 August 2021 


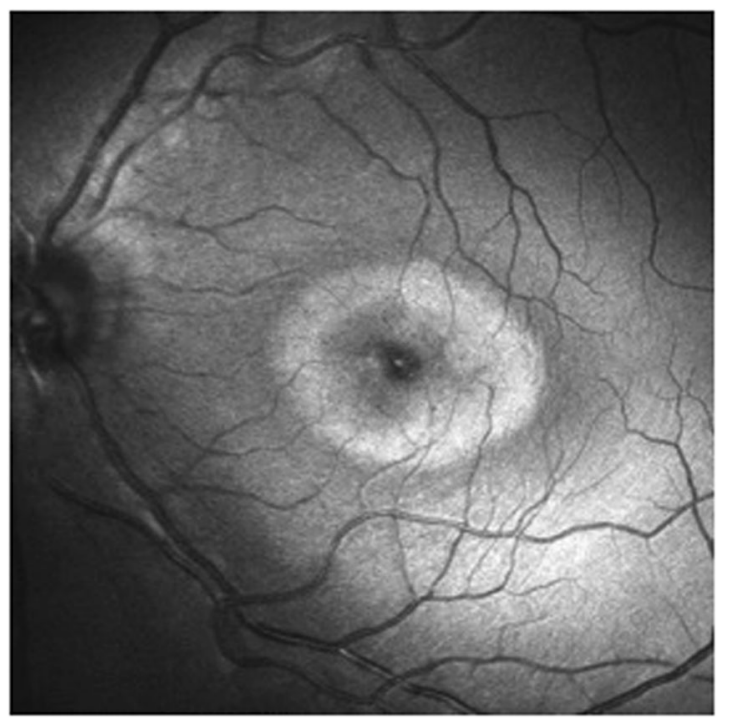

Fig. 1 Blue light reflectance (BLR) in MacTel. BLR image of a 65 -year-old MacTel patient demonstrating the changed reflectance in the 'MacTel area'.

pattern in BLR images may, however, be influenced by several factors. Most importantly, dark adaptation has a profound effect on this finding [31], but image artefacts, a crystalline lens, vitreous opacities and technical factors, including the type of SLO used, also have an effect on BLR imaging [32]. In addition, BLR does not change much over time and seems rather static throughout the course of the disease. This makes it more likely a good diagnostic feature, but not a good outcome measure.

One-wavelength autofluorescence (FAF). Normal one-wavelength $(488 \mathrm{~nm})$ macular fundus autofluorescence (FAF) images demonstrate several changes in MacTel [33]. The most common finding is a relatively increased macular autofluorescence attributed to the characteristic loss (or redistribution) of macular pigment (MP) in eyes of patients with MacTel (see Section "Dual-wavelength autofluorescence (DWAF)"). Yellowish MP absorbs the excitation light used in FAF imaging, which leads to the darker appearance of the fovea where MP physiologically has its highest density in normal eyes [8,34-36]. Focal loss or redistribution of MP results in a relative increase in signal. A very limited temporal wedgeshaped loss of MP may be one of the earliest signs of MacTel (Fig. 2a) and in advanced cases, the entire 'MacTel area' may demonstrate an oval increase in FAF, while increased MP density surrounding the MacTel area may appear as an oval-shaped border of decreased FAF [8].

An increase of the FAF signal can also be caused by other structural changes in MacTel. Photoreceptor atrophy can result in increased FAF, either due to an increase of autofluorescent photoreceptor debris, or due to reduced absorption of the excitation light by rhodopsin [37] (Fig. 2b). In later stages of the disease, a "mixed" pattern with areas of increased and decreased autofluorescence simultaneously can often be observed. These changes incorporate areas of increased autofluorescence as described above in combination with areas of decreased autofluorescence caused by pigment plaques, but also retinal haemorrhages or small patches of retinal pigment epithelial atrophy (Fig. 2c).

In summary, FAF can reveal early MacTel changes, due to a loss of MP in a small, wedge-shaped sector of the temporal fovea resulting in increased $\mathrm{FAF}$ in the same area, but can also demonstrate different FAF changes in the MacTel area in more advanced cases. Because MacTel changes in FAF are difficult to quantify, this method is more likely a good diagnostic feature, but not a good outcome measure.

Dual-wavelength autofluorescence (DWAF). Because lipofuscin in the foveal retinal pigment epithelium (RPE) is not distributed homogenously, the analysis of the autofluorescence pattern on FAF images does not result in an exact quantification of the central MP. Therefore, in order to obtain a more objective measurement, MPOD maps of relative optical densities at the posterior pole are generated using images at two different excitation wavelengths: $488 \mathrm{~nm}$ (good absorption by MP) and 514 $\mathrm{nm}$ (poor absorption by MP). After digital subtraction of the log reflectance data obtained at the two different wavelengths, a density map image can be created with this DWAF method [38].

In "normal" eyes, a white spot in the fovea with decreasing intensity towards the parafovea is visible on DWAF images, because the MP concentration is highest in the centre. In MacTel patients, this MPOD distribution is changed resulting in a asymmetric MPOD distribution [7, 34-36, 39, 40]. The progression of this MP redistribution can be divided into different classes (Fig. 3: I-III c) [8] and can be quantified with MPOD profiles [36]. Typical features of MPOD images of class I are a triangular segment of reduced MP in the temporal fovea with persistent central accumulation of MP (Fig. 3 I c), of class II a further expansion of the segment and a vanishing of central accumulation (Fig. 3 II c) and of class III an oval effacement of MP centrally, surrounded by a halo of increased MP at 5-7 degrees eccentricity (Fig. $3 \mathrm{III} \mathrm{c}$ ). These classes were associated with an increase in morphological changes (especially photoreceptor loss) on OCT, increasing restrictions in visual function and individual progression during follow-up.

Because the MacTel changes in DWAF can be quantified, but the correlation with functional loss has not been demonstrated, this method is also more likely a good diagnostic feature, but not a good outcome measure.

Fluorescein angiography. The gold standard technique for evaluating vascular changes in MacTel from the original description of the disease by Gass was FA [5, 6]. Characteristic vascular changes in MacTel are visible in the early phase of FA and mainly affect the deep capillary network of the retina $[1,14]$. The visible changes include telangiectatic vessels and dilated, blunted or right-angled veins in different areas during disease progression [11]. The changes in early cases of MacTel are visible temporal to the fovea (Fig. $3 \mathrm{I} a, b$ ) and progress during the natural history of the disease from the temporal edge of the foveal centre towards the nasal edge, often by way of the superior margin of the foveal avascular zone (Fig. 3 ॥l a, b). Interestingly, the central area including the FAZ is often not involved in this process, even when it is surrounded by a ring of vascular abnormalities. Also, the area inferior to the FAZ is typically affected later than all other adjacent areas (Fig. $3 \mathrm{III}$ a, b). The distribution of these vascular changes correlates with the "staining" of the perivascular extracellular matrix in the late phase of FA. This characteristic may be different from "leakage" as seen in other vascular diseases, because it is not associated with retinal oedema and thickening and it affects vessels located on the level of the inner nuclear and outer plexiform layers, i.e., in the deep capillary network of the macula, possibly due to changes in the surrounding regulatory structures.

Because the vascular MacTel changes in FA are typical but difficult to quantify, FA is a very valuable diagnostic feature, but not a good outcome measure.

Spectral domain-optical coherence tomography (SD-OCT) SD-OCT B-scan: Morphological changes observable in SD-OCT images are highly characteristic of MacTel type 2 [1, 11, 13$20,41,42]$. These include a thinning of the central retina, 

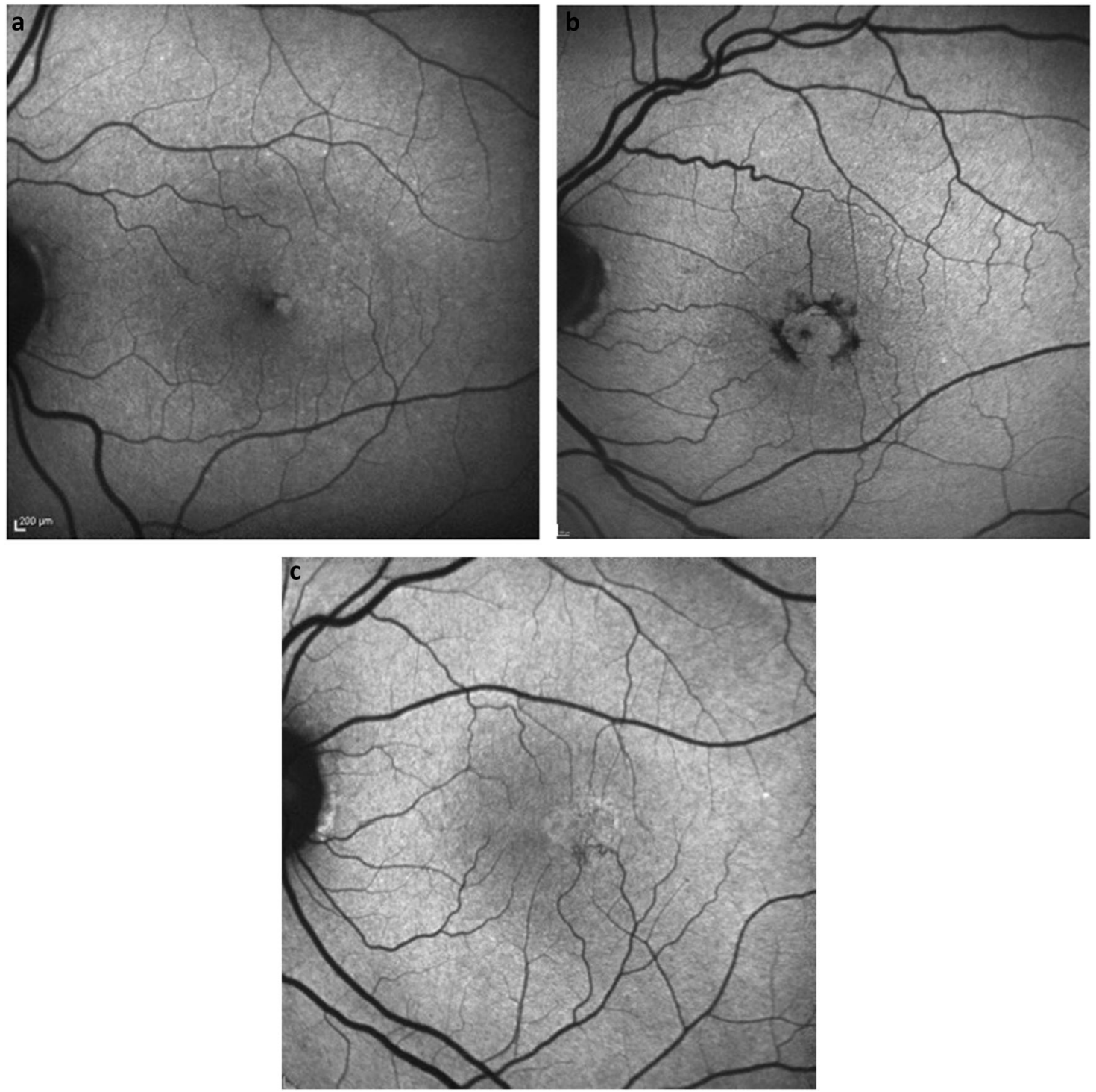

Fig. 2 a-c Changes in autofluorescence in MacTel. A temporal wedge of increased autofluorescence can often be observed as an early sign of MacTel, which is attributed to a redistribution/loss of macular pigment (a). Pigment plaques correlate with a blockage of underlying autofluorescence signal and thus a decrease in autofluorescence signal (b). Vascular changes, such as blunted venules and ectatic macular capillaries, can often be observed temporal to the fovea (c).

low-reflective spaces ('cavities') in the inner and OR, and a focal loss of the EZ (also known as a break in the IS/OS layer), representing the photoreceptor layer. Because photoreceptor loss occurs later in the disease progression, a "normal" OCT scan can be observed in early MacTel cases, where BLT, FAF, DWAF and FA changes are already visible (Fig. 3 I d). This EZ loss typically starts temporal to the foveal centre (Fig. $3 \mathrm{II} \mathrm{d}$ ), progresses to involve the foveal centre, later extending also to the nasal macula (Fig. $3 \mathrm{III}$ d) [14]. This loss of the EZ has been demonstrated to correlate closely with focal retinal function loss as measured by mesopic microperimetry, electrophysiology (multifocal ERG) and-once it affects the foveal centre-by loss of BCVA [13-18, 41].

The progression of EZ loss with increasing disease duration has been demonstrated in several studies $[13,16,18,20]$, but the nonlinearity of this process, with more rapid progression after the start of EZ loss, has also been described [19]. Because of the highly significant correlation between morphology and function, EZ loss may also be a parameter for the disease severity of MacTel in a given case, and a "disease severity scale" (DSS) based on SD-OCT images has been developed (Fig. 3 I-III d) [24]. A very good correlation of this DSS with the area and the progression of photoreceptor and EZ loss, as well as the severity and progression of vascular changes analyzed with OCTA [20, 24], has been described. Because this DSS using foveal SD-OCT scans is easily applicable in clinic, it allows an estimation of the individual "stage" of a given case after confirming the diagnosis with other described imaging methods. The proposed scale certainly has limitations. Establishing the position of the foveal centre accurately in advanced MacTel may be challenging, as the photoreceptor matrix, the distribution of luteal pigment, and the foveal contour are all likely to be affected by the disease. Although the shape of the foveal avascular zone may also be affected, it is advisable to include this vascular area in determining the position of the foveal centre, especially in more advanced disease. Furthermore, other OCT changes like inner retinal cysts, outer cavitation, and outer intraretinal pigment proliferation are also characteristic morphological changes in MacTel and may be included in a more sophisticated classification in the future. 

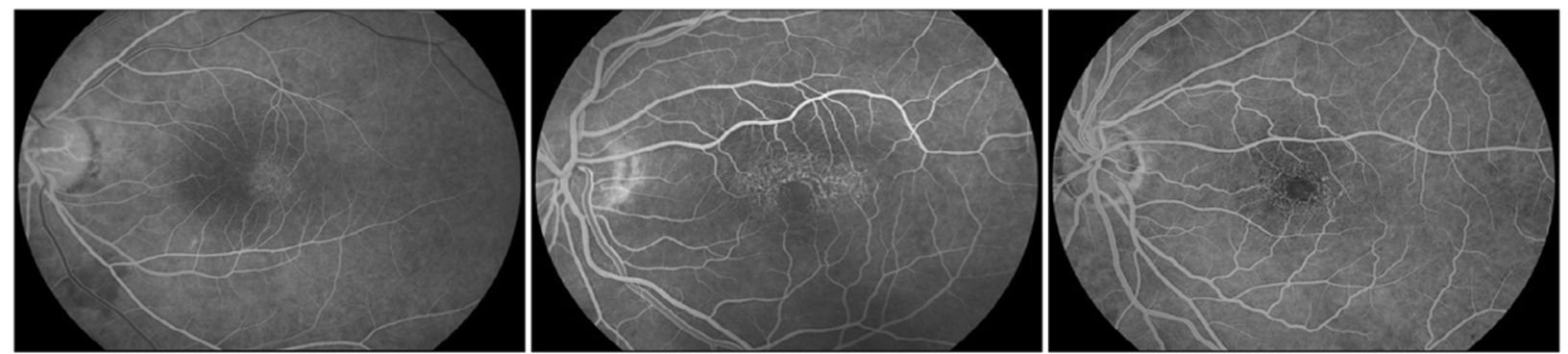

a
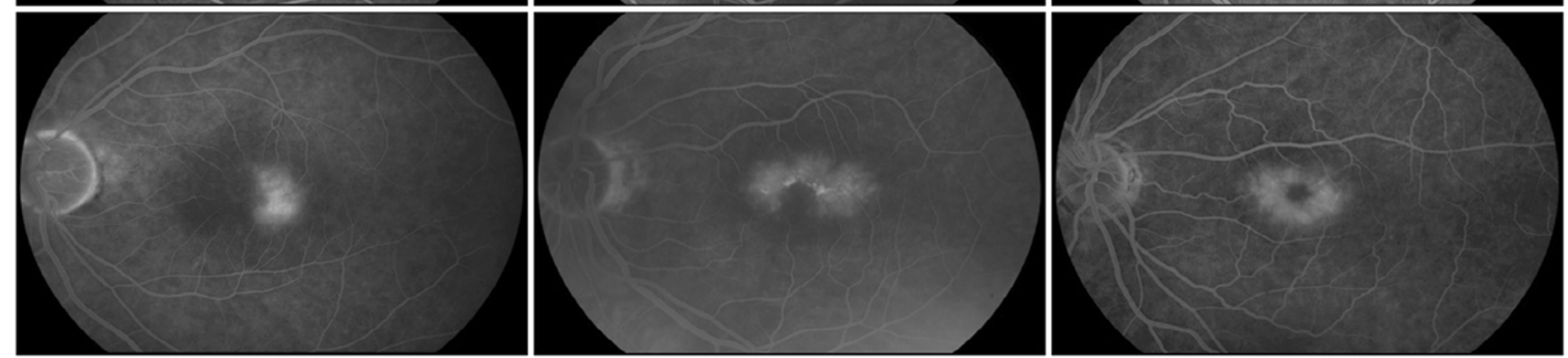

b
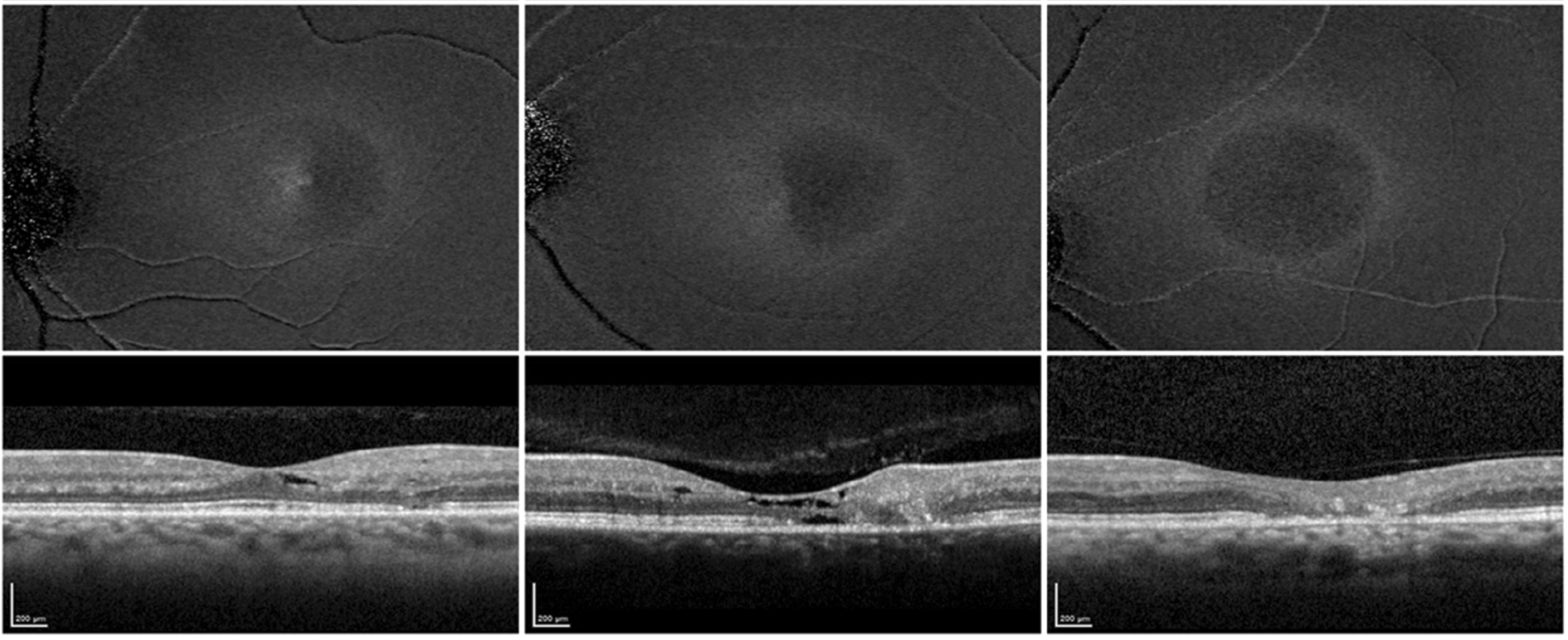

Fig. 3 FA, DWAF and OCT imaging in MacTel. a early FA image; b late FA image, c MPOD with DWAF, $\mathbf{d}$ foveal scan SD-OCT. I a-d "early" MacTel case (DSS grade 1). II a-d: "more advanced" MacTel case (DSS grade 2). III a-d: "advanced" MacTel case (DSS grade 3).

In addition, it has been observed that in some MacTel patients, EZ loss was associated with the presence of outer retinal hyperreflective material $[20,42,43]$. These are often associated with the presence of vascular networks in the OR $[20,42,43]$ or retinochoroidal anastomosis on OCT angiography [22, 23, 44]. Since this hyperreflective material is always present in the OR but sometimes also extends into the inner retina, the MacTel consortium introduced the name "OR associated hyperreflectivity" (ORaH) for these lesions (Fig. 4). These ORaH are associated with the progression and the severity of the disease (DSS) [20] and most often visible in more advanced cases with EZ loss including the fovea (DSS grade 3). On OCT, the size of ORaH as well as their extend into the inner retina and their contact with the RPE were variable. On OCTA, nearly all cases studied showed a vascular complex in the OR at the location of the ORaH [20,43, 44]. In addition, $\mathrm{ORaH}$ are associated with hyperpigmentation. These results are consistent with the concept of ORaH representing fibrovascular complexes in the OR with RPE proliferation after contact with the RPE. Whether these changes are relevant for treatment effects in ongoing clinical trials $[43,45-47]$ has to be evaluated in the future.
Because the length of EZ loss in MacTel visible on SD-OCT foveal scans corresponds with photoreceptor loss and functional deficits in microperimetry and can be quantified, it may be a good diagnostic feature and a possible outcome measure. But although the length of EZ loss may correspond with the area of photoreceptor loss, 'en face' OCT measurements of the area of EZ loss are more precise and reproducible, as there is often an asymmetry in the diameter in different axis.

'En face' SD-OCT: 'En face' SD-OCT imaging of the retina is intuitive for the examiner and permits 2D assessment of lesion extent, topographical analysis and close comparisons with other imaging modalities (Fig. 5). Using volume scans from a standard SD-OCT with a real-time eye-tracking system and an automated segmentation of retinal layers, areas of EZ loss can be identified and quantified $[13,41,46]$. Within the area of the $E Z$ loss, regions with very low backscatter may also be present. These correspond to the cross sections of OR spaces with low reflectivity. In B-scans, these spaces give the impression of degenerative cavities. The material within these spaces does not seem to take up fluorescein, even in the late phase of FA. Insular areas with a reflectivity closer 


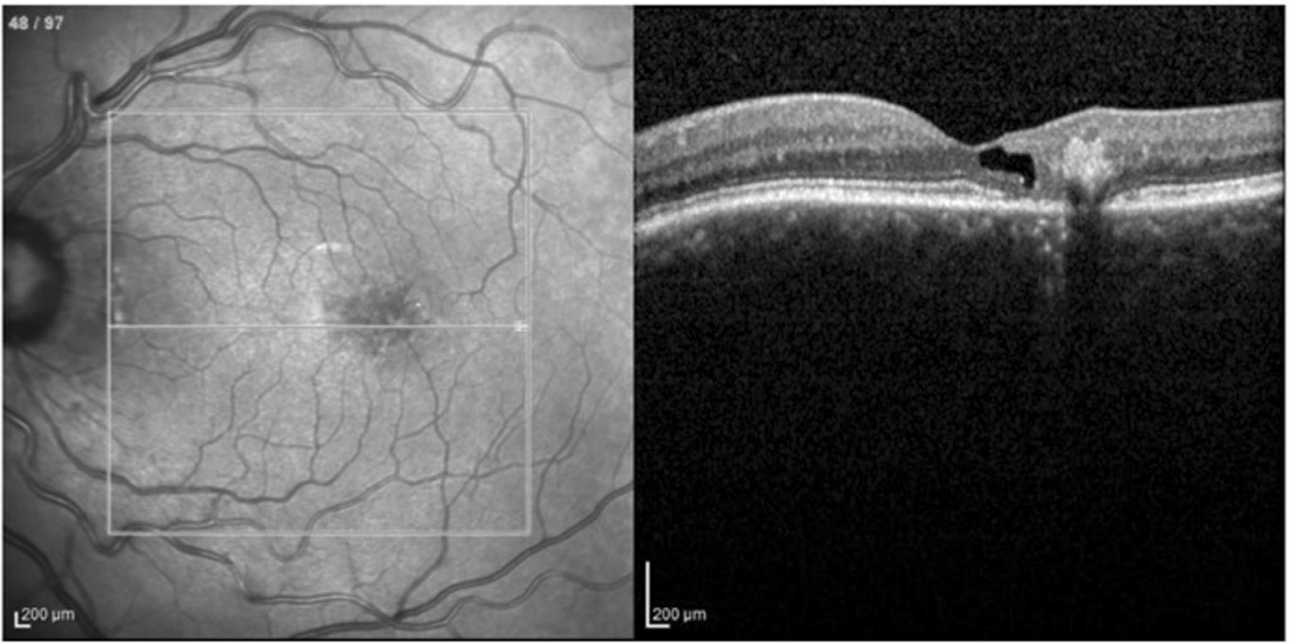

Fig. 4 Foveal SD-OCT scan in MacTel. EZ loss and OR associated hyperreflectivity (ORaH) in the centre.

to that of the EZ line were also apparent within the break. These may correspond to areas with preserved EZ, but may also be due to "collapsed" inner retinal layers towards the RPE [41]. In general, however, the area of EZ loss as seen on 'en face' SD-OCT images is the best method to quantify photoreceptor loss in MacTel patients. The robustness of these measurements has been proven on repeated images in individual patients [41]. Because of the very precise and reproducible quantification of the area of EZ loss and the significant correlation of the area of EZ loss with functional scotoma in microperimetry, the area of EZ loss has been accepted as a clinically relevant parameter for prospective Phase 1 and 2 trials using ciliary neurotrophic factor (CNTF) implants in MacTel patients $[45,46]$.

The development and progression of photoreceptor loss in MacTel may often only start several years after the diagnosis has been established already by BLR, MPOD redistribution, FAF or FA and OCT-A. Once the EZ loss has started-as mentioned most often temporal to the fovea-a more rapid and exponential increase of photoreceptor death can be observed [19]. This increase gets slower once the "end stage" of this process is approached and at this "end stage" the EZ loss covers the complete 'MacTel area' [26]. In addition, en face OCT can be used to quantify the area of ORaH in MacTel (Fig. 6a) [43]. In this analysis, ORaH in MacTel was again associated with severe functional impairment, leading to an almost complete loss of retinal sensitivity as observed on microperimetry [43].

Because the area of EZ loss in MacTel visible on 'en face' SD-OCT corresponds with photoreceptor loss and functional deficits in microperimetry and can be precisely and reproducibly quantified, it is a very good outcome measure for clinical investigations on the progression of MacTel and is already being used in ongoing clinical trials [45-47].

Optical coherence tomography angiography (OCT-angiography, OCT-A). OCT-A is a new method to visualize the choroidal and retinal vasculature based on flow characteristics [47]. This noninvasive method can demonstrate the macular vasculature in three dimensions without the injection of dye. The superficial and deep retinal vascular capillary plexus can be visualized, as well as the normally avascular OR [24]. OCT-A studies have demonstrated that the earliest vascular changes in MacTel occur temporal to the fovea in the deep capillary network [48]. As the disease progresses, the temporal superficial capillary network becomes involved, as well as the nasal capillary networks in both vascular layers (Fig. $6 a-c$ ). Because OCT-A is based on numeric grey values, this method enables a description especially of vascular patterns and parameters with mathematical methods $[49,50]$. Significant differences in vascular parameters with respect to a decrease in vascular density, total length of vessels, number of vessel segments and fractal dimension (parameter for vessel network complexity) are seen among all DSS grades of SD-OCT disease severity [24]. Using this mathematical description of vascular patterns, the subjective characterization of changes visible temporal or nasal to the fovea in different vascular layers $[22,23,48,51]$ could be quantified by early changes (DSS grade 1) in the deep capillary network temporal to the fovea [24]. In more advanced cases (DSS grade 2 and 3), the temporal superficial capillary network demonstrated similar changes, and with further progression a rarefaction of the vascular pattern also developed nasal to the fovea in both the superficial and deep capillary networks [24]. Therefore, a "sequence" of vascular changes can be described with this mathematical analysis, which correlates significantly with the progression of photoreceptor and EZ loss in SD-OCT. Certainly, further OCT-A parameters and especially the acircularity of the foveal avascular zone could be added to describe the vascular patterns and changes during the course and progression of MacTel [42, 44, 52].

In addition, vascular complexes in the OR were often present at the location of the ORaH on OCT-A (Fig. 7a, b) $[20,42,44]$. A lack of OCT-A flow signals could be only be detected in very early stages of the development of ORaH [42]. Increasing size of this OR vascular complex correlated with progressive photoreceptor loss. Moreover, these complexes were often connected to the choriocapillaris ("retinochoroidal anastomosis", RCA) $[20,22,23,44]$.

There are different explanations for the OR vascular complex visible in MacTel. On the one hand, Spaide [44] described this finding as a result of subsidence of the deep capillary network after the loss of OR photoreceptors. This descended and dilated deep capillary network may get contact to the choriocapillaris and may form RCA $[20,22,23]$, which may increase in number and topographic distribution over time. On the other hand, Gaudric [42] suggested that after the loss of photoreceptors in MacTel, new vessels may migrate from the deep capillary network towards the OR forming "OR capillary proliferations". The associated flow signals at the level of the RPE can be projection artefacts [42] or represent RCA after the OR vascular complex come into contact with the choriocapillaris $[20,22,23,44]$. The migration of RPE cells along the vascular network after contact of the OR vascular complex with the RPE 

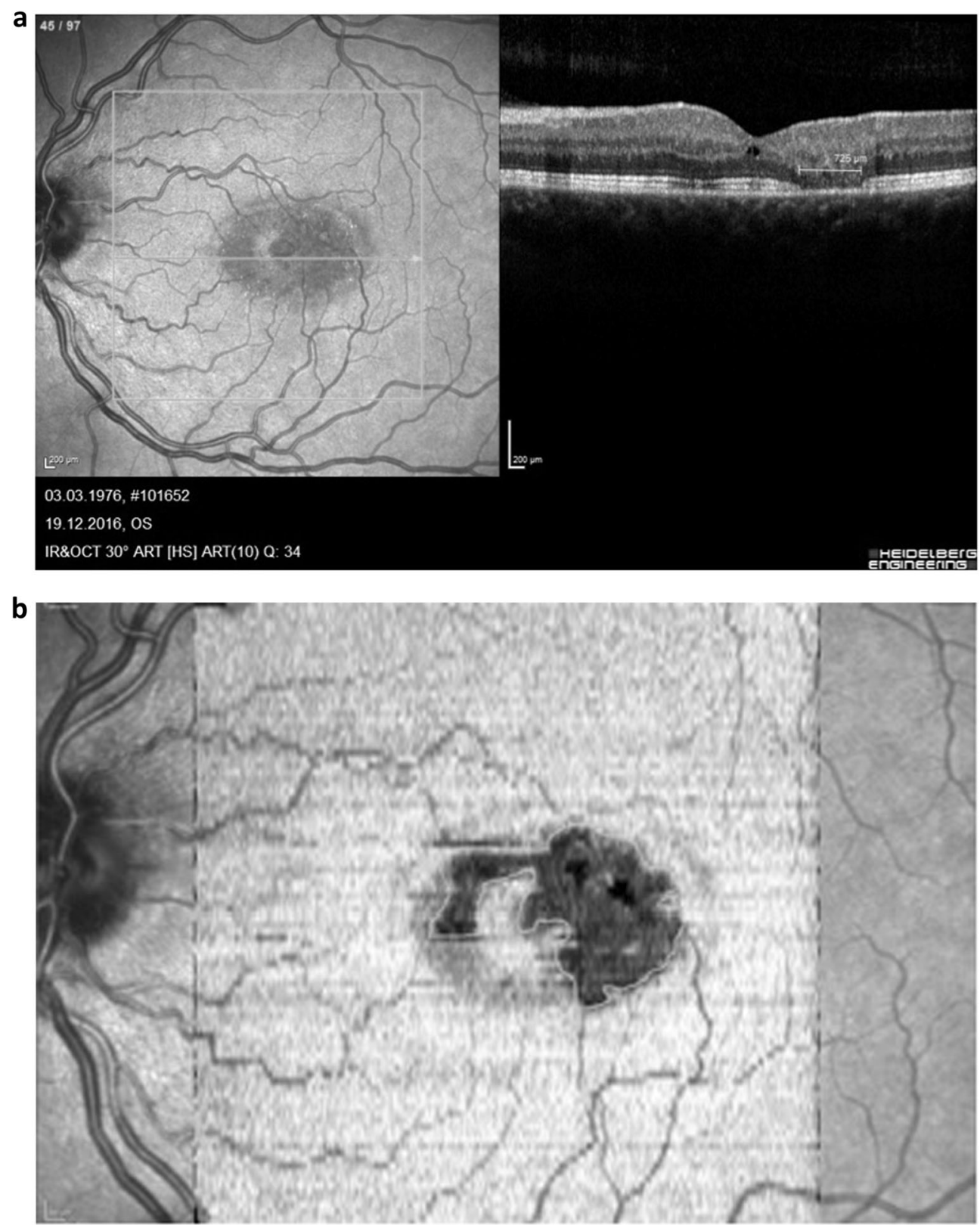

Fig. 5 OCT in MacTel. Area of EZ/photoreceptor loss in SD-OCT (a) and en face OCT (b).

can in both circumstances result in additional intraretinal hyperpigmentation [20, 42, 53]. Therefore, the major conclusions from these studies are that OR vascular complexes are only seen in eyes with photoreceptor loss, but that loss of photoreceptors may not always be associated with these vascular changes. In addition, whilst retinal telangiectasis occurs in some cases of photoreceptor loss, in general it is unusual and common only in retinitis pigmentosa due to Crumbs homologue 1 (CRB-1) mutation [54] and in the very-low-density-lipoprotein knock out mouse [55].

The association between $\mathrm{ORaH}$ on OCT and OR vascular complex on OCT-A has been described in other studies as "OR neovascularisation" [20, 42, 43]. However, using the term "neovascularisation" for OR vascular complexes visible as ORaH in OCT should be discussed. First, as mentioned above, the origin of the OR vascular complex has yet to be elucidated as to whether it represents an OR capillary proliferation [42] or as a collapse of preexisting but changed deep retinal capillaries [44].
Second, in AMD the term choroidal or macular "neovascularisation" (CNV, MNV) is most often associated with exudative changes initiating anti-VEGF (vascular endothelial growth factor)-therapy [56]. In MacTel, only a very small number of patients with $\mathrm{ORaH}$ develop "definitive" exudative subretinal neovascularisation associated with thickening of the retina or intra- or subretinal bleeding $[5,6,25]$. Only in this small group of MacTel patients, anti-VEGF therapy is recommended and helpful [25]. In all other MacTel patients, anti-VEGF therapy has been demonstrated to be unsuccessful and may even cause long-term harm [57, 58]. However, MacTel may also occur in older individuals with drusen and it has to be investigated whether other causes of choroidal MNV, such as neovascular age-related macular degeneration, may be present.

In conclusion, the vascular structures in the OR represent an OR vascular complex, which is visible in OCT as ORaH and demonstrate no exudative characteristics. This OCT characteristic more commonly occurs with disease progression and may 

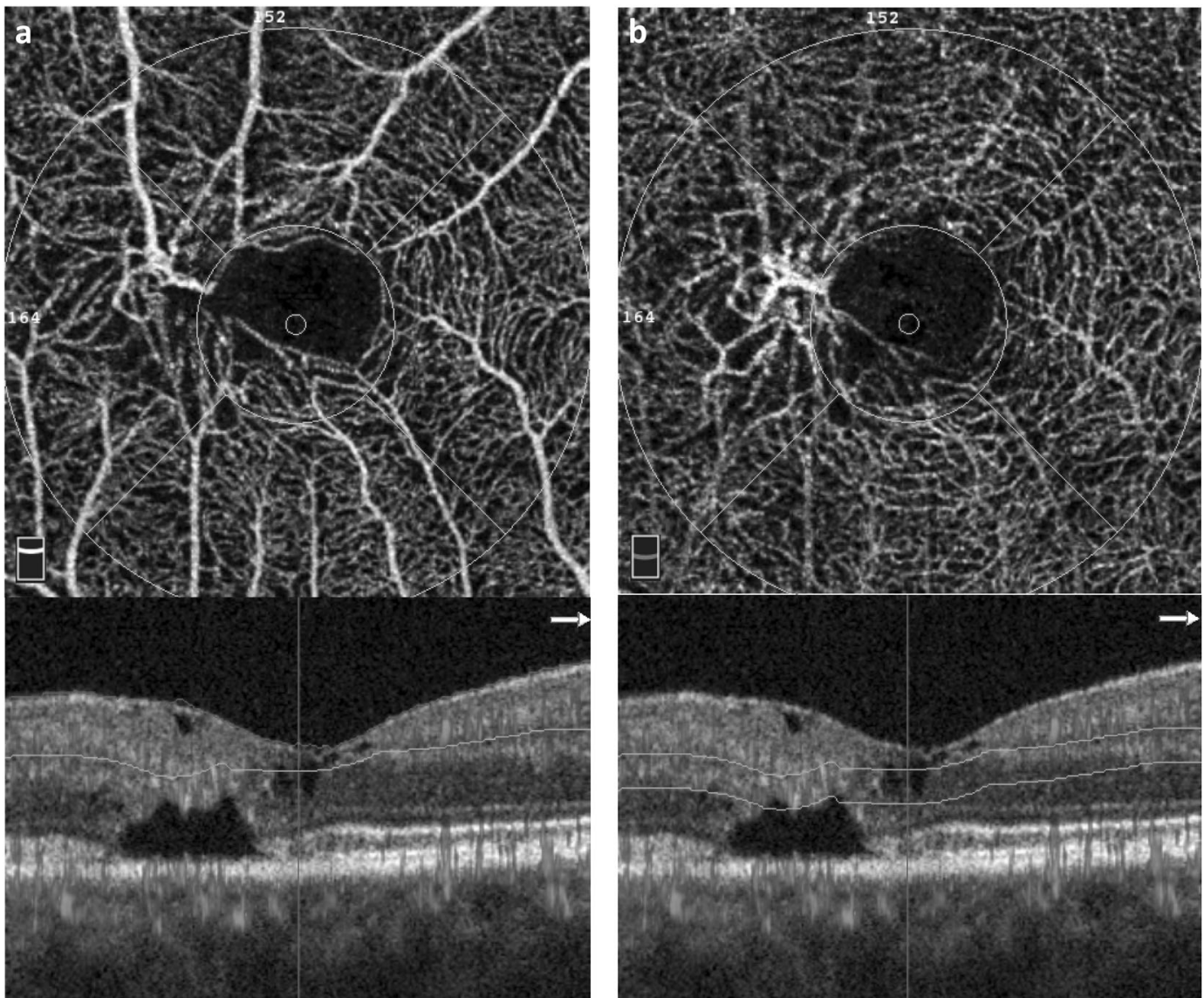

Fig. 6 a, b OCTA images in MacTel. Vascular changes in the superficial (a) and deep (b) capillary network.

be the result of a subsidence of the deep capillary network or of new vessels growth from the deep capillary network into the OR. Only in a few cases will this OR vascular complex develop characteristics of exudative neovascularisation and should therefore be differentiated from exudative MNV due to other causes [56].

As OCT-A images the vascular changes in MacTel and these changes can be differentiated and located in different retinal layers, this method is a good diagnostic feature. The decision of whether the quantification of these vascular OCT-A changes can be used as a possible outcome measure for MacTel progression can only be made after a good correlation with morphological and functional parameters is demonstrated.

\section{Endpoints for clinical trials}

BCVA and microperimetry. Although slowly progressive, MacTel may lead to a bilateral loss of central vision and as of yet, there is no approved therapy. Normal functional analysis such as BCVA only decreases if the photoreceptor and EZ loss occurs at the fovea [19] and in addition does correlate well with disease progression [19]. Because of this very slow decrease in function measured by BCVA (i.e., 1 letter per year), it would need many years and a very high number of participants to complete a study. Therefore, BCVA is not a good parameter for treatment outcome. In addition, reading difficulties resulting from a pre-fixation scotoma (caused by bi-temporal photoreceptor loss) may occur before the loss of central vision and can handicap patients dramatically, which is not reflected by BCVA alone.

Microperimetry may be a better option to quantify functional loss. Because the scotoma resulting from photoreceptor loss in MacTel patient is sharply demarcated and profound, this technique has been evaluated as a very good functional parameter to quantify the functional deficits in MacTel patients $[1,13,15,16,18]$. Another important observation was that these deficits in microperimetry correlate highly significantly with the morphological quantification of photoreceptor loss in SD-OCT (length of EZ loss) and 'en face' OCT (area of EZ loss). Therefore, microperimetry and EZ loss analysis are both very good quantifiable parameters for the severity and progression of MacTel $[13,15,16,41,45,46]$.

$S D$-OCT: length (foveal scan) and area ('en face' OCT) of EZ loss. To confirm therapeutic efficacy in treatment trials by reducing the progression of photoreceptor loss in MacTel, it is of considerable importance to provide outcome measures for the observation and quantification of disease severity and progression that are precise, accurate and reproducible. All these characteristics could be demonstrated for the quantification of EZ loss on OCT.

First, previous studies demonstrated that area measurements of EZ loss are a very good surrogate parameter for the severity and progression of the disease, as it corresponds closely with functional loss especially as quantified by microperimetry $[13,15,16,41,45,46]$.

Second, this morphological quantification of photoreceptor loss is not as compliance-dependent as microperimetry, cannot be influenced by the participant and has a lower intersession variability. Therefore, it is a more objective outcome parameter.

Third, although there is a good correlation between length and area of the EZ loss [19, 20], the asymmetric configuration of the EZ loss area makes 'en face' OCT analysis and measurement of the area of photoreceptor loss more reliable method than SDOCT alone to determine the functionally relevant structural correlate of MacTel disease severity [41]. 

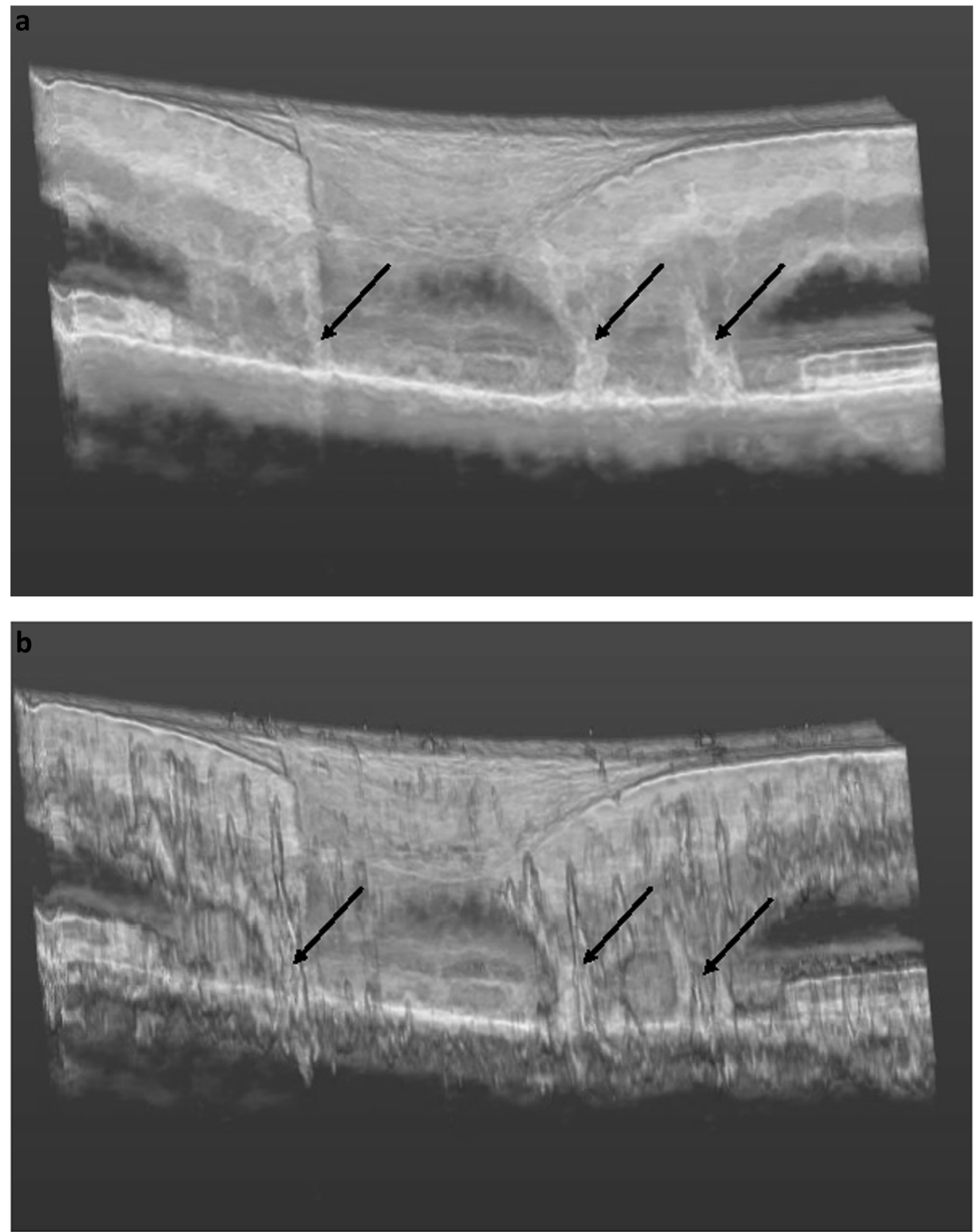

Fig. 7 3D OCT in MacTel. a, b 3 D reconstruction of SD-OCT volume scan (a) and OCT-A volume scan (b) with three ORaH and RCA (arrows).

For these reasons 'en face' OCT analysis was accepted by the FDA as an study "endpoint". It has been already used and explored in a phase 1 and 2 clinical trial of an intravitreal encapsulated device producing CNTF in MacTel $[45,46]$ and is also used in the ongoing phase 3 trial exploring the efficacy of CNTF implants in the treatment of MacTel.

Progression of the area of EZ loss on 'en face' OCT therefore appears to be the best imaging endpoint for MacTel.

\section{REFERENCES}

1. Charbel Issa P, Gillies MC, Chew EY, Bird AC, Heeren TF, Peto T, et al. Macular telangiectasia type 2. Prog Retin Eye Res. 2013;34:49-77.

2. Powner MB, Gillies MC, Tretiach M, Scott A, Guymer RH, Hageman GS, et al. Perifoveal Müller cell depletion in a case of macular telangiectasia type 2. Ophthalmology. 2010;117:2407-16.

3. Powner MB, Gillies MC, Zhu M, Vevis K, Hunyor AP, Fruttiger M. Loss of Müller's cells and photoreceptors in macular telangiectasia type 2. Ophthalmology. 2013;120:2344-52.
4. Gantner ML, Eade K, Wallace M, Handzlik MK, Fallon R, Trombley J, et al. Serine and lipid metabolism in macular disease and peripheral neuropathy. $\mathrm{N}$ Engl J Med. 2019;381:1422-33.

5. Gass JD, Oyakawa RT. Idiopathic juxtafoveolar retinal telangiectasis. Arch Ophthalmol. 1982;100:769-80.

6. Gass JDM, Blodi BA. Idiopathic juxtafoveolar retinal telangiectasis: update of classification and follow-up study. Ophthalmology. 1993;100:1536-46.

7. Esposti SD, Egan C, Bunce C, Moreland JD, Bird AC, Robson RG. Macular pigment parameters in patients with macular telangiectasia (MacTel) and normal subjects: implications of a novel analysis. Investig Ophthalmol Vis Sci. 2012;53:6568-75.

8. Zeimer MB, Padge B, Heimes B, Pauleikhoff D. Idiopathic macular telangiectasia type 2: distribution of macular pigment and functional investigations. Retina. 2010;30:586-95.

9. Charbel Issa P, Berendschot TT, Staurenghi G, Holz FG, Scholl HP. Confocal blue reflectance imaging in type 2 idiopathic macular telangiectasia. Investig Ophthalmol Vis Sci. 2008;49:1172-7.

10. Sallo FB, Leung I, Zeimer M, Clemons TE, Dubis AM, Fruttiger $M$, et al. Abnormal retinal reflectivity to short-wavelength light in type 2 idiopathic macular teleangiectasis. Retina. 2018;38:S79-88. 
11. Tzaridis S, Heeren TFC, Mai C, Thiele S, Holz FG, Charbel Issa $P$, et al. Right-angled vessels in macular telangiectasia type 2 . Br J Ophthalmol. 2019. https://doi.org/ 10.1136/bjophthalmol-2018-313364. Online ahead of print.

12. Gaudric A, Ducos de Lahitte G, Cohen SY, Massin P, Haouchine B. Optical coherence tomography in group $2 \mathrm{~A}$ idiopathic juxtafoveolar retinal telangiectasis. Arch Ophthalmol. 2006;124:1410-9.

13. Sallo FB, Peto T, Egan C, Wolf-Schnurrbusch UE, Clemons TE, Gillies MC, et al. The IS/OS junction layer in the natural history of type 2 idiopathic macular telangiectasia. Investig Ophthalmol Vis Sci. 2012;53:7889-95.

14. Sallo FB, Leung I, Clemons TE, Peto T, Bird AC, Pauleikhoff D. Multimodal imaging in type 2 idiopathic macular teleangiectasis. Retina. 2015;35:742-9.

15. Mukherjee D, Lad EM, Vann RR, Jaffe SJ, Clemons TE, Friedlander M, et al. Correlation between macular integrity assessment and optical coherence tomography imaging of ellipsoid zone in macular telangiectasia type 2. Investig Ophthalmol Vis Sci. 2017;58:291-9.

16. Heeren TFC, Kitka D, Florea D, Clemons TE, Chew EY, Bird AC, et al. Longitudinal correlation of ellipsoid zone loss and functional loss in Macular Telangiectasia Type 2. Retina. 2018;38:S20-26.

17. Okada M, Robson AG, Egan CA, Sallo FB, Esposti SD, Heeren TFC, et al. Electrophysiological characterization of Macular Telangiectasia Type 2 and structurefunction correlation. Retina. 2018;38:S33-42.

18. Peto T, Heeren TFC, Clemons TE, Sallo FB, Leung I, Chew EY, et al. Correlation of clinical and functional progression with visual acuity loss in Macular Telangiectasia Type 2. MacTel Project Report No. 6-The MacTel Research Group. Retina. 2018;38:S8-13.

19. Pauleikhoff $D$, Bonelli R, Dubis AM, Gunnemann F, Rothaus $K$, Charbel Issa $P$, et al. Progression characteristics of ellipsoid zone loss in macular teleangiectasia type 2. Acta Ophthalmol. 2019;97:998-1005.

20. Mueller S, Gunnemann F, Rothaus K, Book M, Faatz H, Bird AC, et al. Incidence and phenotypical variation of outer retina-associated hyperreflectivity in macular telangiectasia type 2. Br J Ophthalmol. 2021;105:573-6.

21. Gaudric A, Krivosic V, Tadayoni R. Outer retina capillary invasion and ellipsoid zone loss in Macular Teleangiectasia Type 2 imaged by OCT angiography. Retina. 2015;35:2300-6.

22. Spaide RF, Yannuzzi LA, Maloca PM. Retinal-choroidal anastomosis in macular teleangictasis type 2. Retina. 2018;38:1920-9.

23. Breazzano MP, Yannuzzi LA, Spaide RF. Characterizing retinal-choroidal anastomosis in macular teleangiectasia type 2 with optical coherence tomography angiography. Retina. 2020;40:92-8.

24. Pauleikhoff D, Gunnemann F, Book M, Rothaus K. Progression of vascular changes in macular telangiectasia type 2: comparison between SD-OCT and OCT angiography. Graefes Arch Clin Exp Ophthalmol. 2019;257:1381-92.

25. Tzaridis S, Hess K, Friedlander M, Holz FG. Optical coherence tomographyangiography for monitoring neovascularisations in macular telangiectasia type 2 . Br J Ophthalmol. 2021;105:735-40.

26. Heeren TFC, Chew EY, Clemons T, Fruttiger $M$, Balaskas $K$, Schwartz $R$, et al. MacTel Study Group. Macular telangiectasia type 2 - visual acuity, disease endstage and the MacTel area. MacTel Project Report No. 8. Ophthalmology. 2020;127:1539-48

27. Charbel Issa P, Heeren TF, Kupitz EH, Holz FG, Berendschot TT. Very early disease manifestations of macular telangiectasia type 2. Retina. 2016;36:524-34.

28. Heeren TF, Clemons T, Scholl HP, Bird AC, Holz FG, Charbel Issa P. Progression of vision loss in macular telangiectasia type 2. Investig Ophthalmol Vis Sci. 2015;56:3905-12.

29. Charbel Issa P, Finger RP, Helb HM, Holz FG, Scholl HP. A new diagnostic approach in patients with type 2 macular telangiectasia: confocal reflectance imaging. Acta Ophthalmol. 2008;86:464-5.

30. Bottoni F, Eandi CM, Pedenovi S, Staurenghi G. Integrated clinical evaluation of Type 2A idiopathic juxtafoveolar retinal telangiectasis. Retina. 2010;30:317-26.

31. Jindal A, Choudhury H, Pathengay A, Flynn HW Jr. A novel clinical sign in macular telangiectasia type 2. Ophthalmic Surg Lasers Imaging Retin. 2015; 46:134-6.

32. Okada M, Heeren TFC, Egan CA, Rocco V, Bonelli R, Fruttiger M. Effect of dark adaptation and bleaching on Blue Light Reflectance imaging in Macular Teleangiectasia Type 2. Retina. 2018;38:89-96.

33. Pauleikhoff L, Heeren TFC, Gliem M, Lim E, Pauleikhoff D, Holz FG, et al. Fundus autofluorescence imaging in macular telangiectasia type 2 - MacTel Study Report Number 9: fundus autofluorescence in macular telangiectasia type 2. Am J Ophthalmol. 2021;228:27-34.

34. Zeimer MB, Krömer I, Spital G, Lommatzsch A, Pauleikhoff D. Macular telangiectasia: patterns of distribution of macular pigment and response to supplementation. Retina. 2010;3:1282-93

35. Zeimer MB, Spital G, Heimes B, Lommatzsch A, Pauleikhoff D. Macular telangiectasia-changes in macular pigment optical density during a 5-year followup. Retina. 2014;34:920-8.
36. Zeimer MB, Sallo FB, Spital G, Heimes B, Lommatzsch A, Pauleikhoff D. Correlation of optical coherence tomography and macular pigment optical density measurements in type 2 macular teleangiectasia. Retina. 2016;36:535-44.

37. Theelen $T$, Berendschot $T$, Boon $C J$, Hoyng $C B$, Klevering BJ. Analysis of visual pigment by fundus autofluorescence. Exp Eye Res. 2008;8:296-304.

38. Trieschmann M, Heimes B, Hense HW, Pauleikhoff D. Macular pigment optical density measurement in autofluorescence imaging: comparison of one- and twowavelength methods. Graefes Arch Clin Exp Ophthalmol. 2006;244:1565-74.

39. Helb HM, Charbel Issa P, RL VDV, Berendschot TT, Scholl HP, Holz FG. Abnormal macular pigment distribution in type 2 idiopathic macular telangiectasia. Retina. 2008;28:808-16.

40. Charbel Issa P, van der Veen RL, Stijfs A, Holz FG, Scholl HP, Berendschot $\Pi$. Quantification of reduced macular pigment optical density in the central retina in macular telangiectasia type 2. Exp Eye Res. 2009;89:25-31.

41. Sallo FB, Peto T, Egan C, Wolf-Schnurrbusch UE, Clemons TE, Gillies MC, et al. "En face" OCT imaging of the IS/OS junction line in type 2 idiopathic macular telangiectasia. Investig Ophthalmol Vis Sci. 2012;5:6145-52.

42. Krivosic V, Lavia C, Aubineau A, Tadayoni R, Alain Gaudric A. OCT of outer retinal hyperreflectivity, neovascularization, and pigment in macular telangiectasia type 2. Ophthalmol Retina. 2020;19:2468-6530.

43. Tzaridis S, Friedlander M, Macular Telangiectasia Type 2-Phase 2 CNTF Research Group. Functional relevance of hyper-reflectivity in macular telangiectasia type 2 . Investig Ophthalmol Vis Sci. 2021;62:6. https://doi.org/10.1167/iovs.62.3.6.

44. Breazzano MP, Yannuzzi LA, Spaide RF. Genesis of retinal-choroidal anastomosis in macular telangiectasia type 2: a longitudinal analysis. Retina. 2020;40:92-8.

45. Chew EY, Clemons TE, Peto T, Sallo FB, Ingerman A, Tao W, et al. Ciliary neurotrophic factor for macular telangiectasia type 2: results from a phase 1 safety trial. Am J Ophthalmol. 2015;159:659-66.

46. Chew EY, Clemons TE, Jaffe GJ, Johnson CA, Farsiu S, Lad EM, et al. Effect of ciliary neurotrophic factor on retinal neurodegeneration in patients with macular telangiectasia type 2: a randomized clinical trial. Ophthalmology. 2019;126:540-9.

47. Jia Y, Tan O, Tokayer J, Potsaid B, Wang Y, Liu JJ, et al. Split-spectrum amplitude-decorrelation angiography with optical coherence tomography. Opt Express. 2012;20:4710-25.

48. Zeimer M, Gutfleisch M, Heimes B, Spital G, Lommatzsch A, Pauleikhoff D. Association between changes in macular vasculature in optical coherence tomography- and fluorescein-angiography and distribution of macular pigment in type 2 idiopathic macular teleangiectasia. Retina. 2015;35:2307-16.

49. Faatz $H$, Rothaus K, Gunnemann F, Gutfleisch M, Heimes-Bussmann B, Lommatzsch A, et al. Changes in OCT angiography of Type 2 CNV in neovascular AMD during anti-VEGF treatment. Klin Monatsbl Augenheilkd. 2017;234:1125-31.

50. Faatz H, Farecki ML, Rothaus, Gunnemann F, Gutfleisch M, Lommatzsch A. Optical coherence tomography angiography of type 1 and 2 neovascularisations in agerelated macular degeneration under anti-VEGF therapy: Evaluation of a new quantitative method. Eye. 2019;33:1466-71.

51. Zhang $Q$, Wang RK, Chen $C L$, Legarreta $A D$, Durbin $M K, A n ~ L$, et al. Swept source optical coherence tomography angiography of neovascular macular teleangiectasia type 2. Retina. 2015;35:2285-99.

52. Runkle AP, Kaiser PK, Srivastava SK, Schachat AP, Reese JL, Ehlers JP. OCT angiography and ellipsoid zone mapping of macular telangiectasia type 2 from the AVATAR study. Investig Ophthalmol Vis Sci. 2017;58:3683-9.

53. Leung I, Sallo FB, Bonelli R, Clemons TE, Pauleikhoff D, Chew EY, et al. Characteristics of pigmented lesions in type 2 idiopathic macular teleangiectasia. Retina. 2018;38:43-50.

54. Ray TA, Cochran KJ, Kay JN. The enigma of CRB1 and CRB1 retinopathies. Adv Exp Med Biol. 2019;1185:251-5.

55. Usui-Ouchi A, Usui $Y$, Kurihara $T$, Aguilar $E$, Dorrell MI, Ideguchi $Y$, et al. Retinal microglia are critical for subretinal neovascular formation. JCI Insight. 2020;5: e137317.

56. Spaide RF, Jaffe GJ, Sarraf D, Freund KB, Sadda SR, Staurenghi G, et al. Consensus nomenclature for reporting neovascular age-related macular degeneration data: consensus on neovascular age-related macular degeneration nomenclature study group. Ophthalmology. 2020;127:616-36.

57. Kupitz EH, Heeren TFC, Holz FG, Charbel Issa P. Poor long-term outcome of Anti-VEGF-Therapy in nonproliferative Macular Teleangiectasia Type 2. Retina. 2015;35:2619-26.

58. Tapia Quijada HE, Mantolan Sarmiento C, Gómez Perera S, Serrano García M, Betancor Caro N, Haro Álvarez B. OCT-angiography for diagnosis and response to treatment of subretinal neovascularization secondary to idiopathic macular telangiectasia type 2. Arch Soc Esp Oftalmol. 2021. https://doi.org/10.1016/j. oftal.2020.11.020. Online ahead of print.

\section{AUTHOR CONTRIBUTIONS}

DP: structuring and editing of the manuscript. LP, EYC: editing of the manuscript. 
COMPETING INTERESTS

The authors declare no competing interests.

\section{ADDITIONAL INFORMATION}

Correspondence and requests for materials should be addressed to D.P.
Reprints and permission information is available at http://www.nature.com/ reprints

Publisher's note Springer Nature remains neutral with regard to jurisdictional claims in published maps and institutional affiliations. 